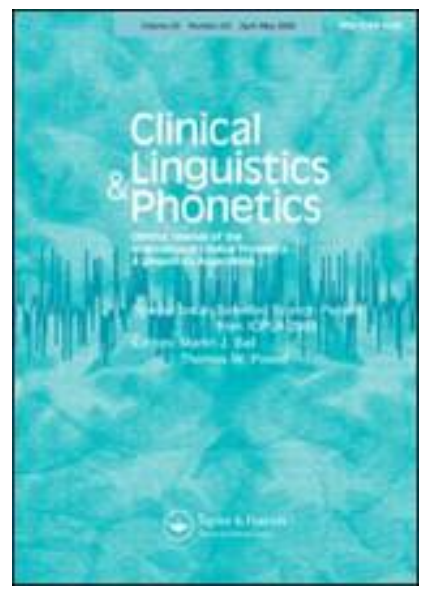

\title{
Validity and reliability of the Intelligibility in Context Scale: European Portuguese version
}

\begin{tabular}{|r|l|}
\hline Journal: & Clinical Linguistics \& Phonetics \\
\hline Manuscript ID & Draft \\
\hline Manuscript Type: & Original paper \\
\hline Keywords: & $\begin{array}{l}\text { intelligibility }<\text { speech, speech production measurement }<\text { speech, } \\
\text { speech disorders, assessment }\end{array}$ \\
\hline \multicolumn{2}{|l}{} \\
\hline
\end{tabular}

\section{SCHOLARONE ${ }^{\text {M }}$ Manuscripts}




\title{
Validity and reliability of the Intelligibility in Context Scale: European Portuguese version
}

\begin{abstract}
Purpose: To evaluate the validity, reliability, sensitivity and specificity of the European Portuguese version of the ICS (McLeod, Harrison, \& McCormack, 2012c).

Methods: Seventy-six children (25 with a parent or teacher concern about how they talked and 51 with no concern) were assessed with the phonetic-phonological test (TFFALPE) to calculate severity measures: percentage of phonemes correct (PPC), percentage of consonants correct (PCC), and percentage of vowels correct (PVC). Parents also filled out a questionnaire about their child's development (e.g. concern about how the child talks). The ICS was then completed by parents to estimate children's intelligibility with different communicative partners.
\end{abstract}

Results: Item-level scores were different according to communicative partners. The mean ICS score for the whole sample was 4.6, showing that children were "usually" to "always" intelligible. The ICS had excellent internal consistency $(\alpha=0.96)$. Children with parental concern about their speech presented significantly lower mean scores $(M=3.91)$ than children without parental concerns $(M=4.78)$. There was a positive correlation between the ICS scores and PPC ( $r=.655)$, PCC $(r=.654)$, and PVC $(r=.588)$. A simple linear model was also obtained between the ICS mean score and the severity measures analyzed. High values were obtained for sensitivity (0.80) and specificity (0.84), using a cut-point of 4.36 . Conclusions: The European Portuguese version of the ICS has good psychometric properties, suggesting it to be a valid tool for estimating children's intelligibility when talking with different communicative partners. Therefore, this version of the ICS can be used as a screening measure for children's speech intelligibility.

Keywords: intelligibility, children, validity, reliability 


\section{INTRODUCTION}

Intelligibility is defined as how well a speaker's speech is understood by listeners (Pascoe, Stackhouse, \& Wells, 2006; Weismer, 2009). Although typically-developing children are mostly intelligible by age four (Gordon-Brannan \& Hodson, 2000), children with speech sound disorders are often highly unintelligible (Lousada, Jesus, Hall, \& Joffe, 2014) which can negatively affect participation in different environments, such as home, school and society (Ertmer, 2010; Hustad, Schueler, Schultz, \& DuHadway, 2012), or with different communication partners (Flipsen, 1995; McLeod, Harrison, \& McCormack, 2012d).

Intelligibility is influenced not only by speech signals, but also by the familiarity of the listener with the speaker, the presence of speech cues, knowledge of the context, and the number of speech samples presented (Flipsen, 1995; Pascoe et al., 2006; Ertmer, 2010). Speech-language pathologists should consider intelligibility not only to establish the diagnosis and decide the need for intervention, but also as an outcome measure to assess the efficacy of the intervention (Williams, McLeod, \& McCauley, 2010; Lousada et al., 2014).

There are two assessment methods to measure intelligibility in children with speech sound disorders: word identification tasks and rating scales (Pascoe et al., 2006; Ertmer, 2010; Miller, 2013). In word identification tasks, listeners write down the words that they understood or select words from multiple-choice alternatives. In a clinical setting, the use of rating scales is potentially quick and easy (Lousada et al., 2014). Typically, this method requires the listener (e.g., a speech-language therapist or a communication partner) to rate speech samples along a continuum of intelligibility (e.g., on a numeric scale where 1 represents totally unintelligible and 5 means totally intelligible) (Ertmer, 2010; Lousada et al., 2014). Although different methods are available, few scales have been studied for their psychometric properties. 
The Intelligibility in Context Scale (ICS; McLeod, Harrison, \& McCormack, 2012) is a scale that has been validated. The ICS requires parents to estimate a child's speech understandability in a range of environmental contexts and by different listeners (immediate family, extended family, friends, acquaintances, teachers, and strangers/unfamiliar people) on a five-point scale $(1=$ never, $2=$ rarely, $3=$ sometimes, $4=$ usually, $5=$ always). The ICS contains seven items that were developed based on the environmental factors listed in the International Classification of Functionality, Disability, and Health: Children and Youth (ICF-CY, World Health Organization, 2007). The total score can be compared with normative data (if available) or as an outcome measure (Phạm, McLeod, \& Harrison, 2017).

The psychometric properties of the ICS were first analyzed on 120 Australian Englishspeaking children (McLeod et al., 2012d), and the results showed good internal consistency $(\alpha=.93)$ and construct validity. Criterion validity was also analyzed through moderate correlations between ICS score and severity measures: PPC $(r=.54)$, PCC ( $r=$ .54), PVC $(r=.36)$. Recently, a study with 803 Australian English-speaking children provided normative data and additional validation of the psychometric properties of the ICS (McLeod, Crowe, \& Shahaeian, 2015), and found that the scale had a high internal consistency $(\alpha=.94)$. The values obtained for sensitivity and specificity were 0.82 and 0.58 , respectively. Concerning criterion validity, significantly low correlations between ICS and percentage of phonemes correct (PPC, $r=0.30)$, percentage of consonants correct (PCC, $r=0.24)$, and percentage of vowels correct (PVC, $r=0.30$ ) were found. The ICS has been translated into more than 60 languages (McLeod et al., 2012c), such as the European Portuguese Escala de Inteligibilidade em Contexto (McLeod, Harrison, \& McCormack, 2012b) and the Spanish Escala de la Inteligibilidad en Contexto: Español (McLeod, Harrison, \& McCormack, 2012a). Some translated versions of the ICS have 
also been validated, including traditional Chinese/Cantonese (Ng, To, \& McLeod, 2014), Slovene (Kogovšek \& Ozbič, 2013), Croatian (Tomić \& Mildner, 2014), and Northern Vietnamese (Phạm et al., 2017). In the different studies, the mean score for typicallydeveloping children was between 4 and 5.

In ICS studies, the participants (children) were usually divided into two groups based on parent or teacher concerns about how the children talked and made speech sounds. This allowed researchers to determine whether the scale was able to distinguish between the groups (McLeod, Harrison, \& McCormack, 2012d; McLeod, Crowe, \& Shahaeian, 2015). For Australian English-speaking children (McLeod et al., 2015), the ICS mean scores were lower for children who were identified by caregivers as having difficulty talking ( $M$ $=3.9)$ compared with those who were not $(M=4.6)$. Thus, this scale can be a useful tool to screen children's speech intelligibility. If there is a need for a relatively quick measure of the children's intelligibility, it can be easily completed by caregivers. This study aims to analyze the psychometric properties of validity and reliability scores for the European Portuguese version of the ICS.

\section{METHODS}

\section{Participants}

Seventy-six children were included in this study, 25 with a parent/teacher concern about how they talked and 51 with no identified concern. None of the children had any biomedical condition (e.g., neurological impairment or intellectual disability). None of the children had been identified as having a persistent hearing impairment, although 11 (14.5\%) caregivers referred to a history of ear infections. All children had shown normalrange nonverbal intelligence ( $>25$ th percentile) on the Portuguese version of Raven's 
Coloured Progressive Matrices (Raven, Raven, \& Court, 2009). European Portuguese was the native language of all participants. Socioeconomic level was determined by crossing two indicators: the occupational group and the instructional level of the person who contributes the most to the family income (Reif, Marbeau, Quatresooz, \& Vancraeynest, 1991).

All ethical procedures were ensured by the Ethics Committee, Research Unit in Health Sciences (reference number 482_02_2018). Prior to any data collection, informed consent was collected from all caregivers.

\section{Tools}

Intelligibility in Context Scale (ICS). The ICS is a seven-item parent-rated measure of children's intelligibility when communicating with people with different levels of familiarity and authority, using a five-point Likert scale.

\section{Phonetic-phonological test (Teste Fonético-Fonológico-Avaliação da Linguagem Pré-Escolar, TFF-ALPE). The children's speech abilities were assessed with 67 single words from the standardized phonetic-phonological test (TFF-ALPE; Lousada et al., 2012; Mendes, Afonso, Lousada, \& Andrade, 2013). The TFF-ALPE allows for the analysis of a range of phonemes (consonants, vowels, and consonant clusters) providing normative data for European Portuguese children. The data obtained (phonetic transcriptions) were used to calculate severity measures (PPC, PCC and PVC) through an automatic tool (FAFA; Saraiva, Lousada, Hall, \& Jesus, 2017).}

Questionnaire for parents. Caregivers filled out a questionnaire intended to characterize children (absence of a biomedical condition, native language, history of ear 
infections) and determine their family background (occupational group and instructional level). The questionnaire also includes a specific question: "Do you have any concerns about how your child talks and makes speech sounds?" with three response options (yes, a little, or no). The children were included in a group of no parental concern about speech and language if their parents answered no, according to McLeod, Crowe, and Shahaeian (2015).

\section{Procedure}

Recruitment. First, children from three kindergartens and two child-care centers were screened by parent and teacher reports to detect those who were having difficulty talking and making speech sounds. Then, 80 children ( 27 who had been identified by their parents and teachers as having problems talking, and 53 who had not) underwent an assessment by a speech-language therapist and a psychologist. The final sample includes 76 children whose parents returned the questionnaire for parents and the ICS. Of those 76 children, there were 25 whose caregivers expressed concern about how they talk and make speech sounds, and 51 whose did not present such concerns.

Assessment. Children were assessed by three experienced pediatric speech-language therapists and two trained speech therapy undergraduate (final year) students. These onehour meetings took place in a quiet room in their kindergarten or child-care center. With the consent of the children and their adult guardians, audio of the assessments was recorded using the software Audacity on a laptop with a built-in microphone. TFF-ALPE was used to assess all children's phonology skills. Phonetic transcriptions were recorded online by examiners, and the audio files were reviewed two days after the assessment 
sessions to check the transcriptions. Parents completed the questionnaire and the ICS after their child's assessment.

Reliability of transcriptions. Point-to-point agreement of all consonants and vowels was calculated for broad phonetic transcriptions of each word on the phonetic-phonological instrument. Interrater reliability between the two undergraduate students was calculated for transcription of words on the TFF-ALPE for $13 \%$ (10 children) of the sample. The interrater reliability for 3,580 phonemes was high (98.13\%). This value is comparable with the agreement level in other studies in disordered child phonology (Shriberg, Tomblin, \& McSweeny, 1999) and is considered adequate to the aim of our study.

\section{Data analysis}

Descriptive statistics were reported as mean, standard deviations for continuous variables, and as counts and percentages for categorical variables. The Kruskal-Wallis test was used to compare three or more independent groups. For two independent groups, the MannWhitney U test was conducted. All the correlations were calculated using the Spearman Rank test. The non-parametric test choice was related to the rejection of the normality assumption for the most of the cases studied. Notably, the Pearson correlation results were similar to the ones presented by the Spearman Rank test.

Linear regression models for the prediction of severity measures (PVC, PCC, PFC) were established. Regression ANOVA was tested for the significance of the slopes and the residual's normality was confirmed by visual inspection of the PP plot.

To evaluate internal consistency of the ICS, Cronbach's alpha was calculated. The sensitivity and specificity were evaluated using a Receiver Operative Characteristic 
(ROC) based on ICS and the parent's opinion. The area under the curve (AUC) and the correspondent $95 \%$ confidence interval (CI) were calculated.

All statistical analyses were performed using SPSS ${ }^{\circledR}$ Software, version 24.0 (SPSS Inc., Chicago, IL) and p-values under 0.05 were considered significant.

\section{RESULTS}

\section{Sociodemographic and sample characterization}

Among the 76 children who participated in the study, more of them were male $(n=44$, $57.9 \%)$ than female $(n=32,42.1 \%)$. The children's ages ranged from 47 to 74 months $(M=60.58, \mathrm{SD}=8.05)$. The majority of the sample $(72.4 \%)$ presented a high or mediumhigh socioeconomic status. Eleven $(14.5 \%)$ caregivers referred to a history of ear infections (see table 1).

Insert table 1 about here

\section{Descriptive statistics}

The effect of the demographic variables of gender, age, and socioeconomic status on ICS scores and severity measures was analyzed (see table 2). There were no significant differences between ICS scores based on gender $(p>0.05)$ or socioeconomic status $(p>$ 0.05). However, there were significant differences between the mean ICS scores based on age group $(\mathrm{p}<0.01)$ and parental concern about speech sound production $(\mathrm{p}<0.001)$. Concerning severity measures, there was a significant mean difference between the PCC for gender $(\mathrm{p}<0.05)$ and age groups $(\mathrm{p}<0.01)$, and the PFC only for age groups $(\mathrm{p}<$ 0.05). Parent evaluation presents a significant effect on all severity measures $(p<0.001)$. 
Insert table 2 about here

The results of the ICS obtained with the five-point Likert scale $(1=$ never, $2=$ rarely, $3=$ sometimes, $4=$ usually, 5 = always) are presented in table 3 . A mean average total score of $4.49(\mathrm{SD}=.60)$ was obtained for the whole sample. Mean scores of the seven ICS items indicated that parents' ratings differed by communication partner, being highest for themselves $(M=4.75)$, similar for teachers, immediate family, and friends $(M=4.61, M$ $=4.55$ and $M=4.50$, respectively), and lowest for acquaintances $(M=4.41)$, extended family $(M=4.37)$ and strangers $(M=4.33)$.

Always was the most common response across all seven types of communication partners: parents $(77.6 \%)$, immediate family $(60.5 \%)$, extended family $(50.0 \%)$, friends $(61.8 \%)$, acquaintances $(53.9 \%)$, teachers $(54.5 \%)$ and strangers $(51.3 \%)$. Few cases were rated as rarely or never for all seven types of communication partners.

Insert table 3 about here

\section{Validity and reliability of the Intelligibility in Context Scale (ICS)}

Internal consistency and correlation between items. Moderate to high correlations (ranging from $r h o=.62$ to $r h o=.94, p=.001$ ) were obtained between seven of the items on the ICS using bivariate nonparametric correlation analysis (Spearman's rho). Only one moderate correlation was observed between parents and extended family members (rho $=0.62)$. Internal reliability of the ICS was calculated using Cronbach's alpha $(\alpha=0.96)$, indicating a high internal consistency (see table 4).

Insert table 4 about here 
Criterion validity. Criterion validity of the ICS was analyzed for 76 children (25 whose caregivers presented concerns about how they talk and 51 who did not present any concern) who were assessed with the TFF-ALPE. Criterion validity shows a degree of overlap between two tools that measure similar skills (Gay, 1985). In the present study, the ICS was compared with the participant's PPC, PCC, and PVC obtained through data from the TFF-ALPE. Bivariate correlation analysis (Pearson's $r$ ) indicated that the ICS mean score was positively correlated with PPC $(r=.655), \operatorname{PCC}(r=.654)$, and PVC $(r=$ .588). A simple regression model was also established (see figure 1), indicating a linear relationship between the ICS mean score and the severity measures analyzed (PPC, PCC and PVC). The proportion of variability explained by those models ranged from $49.8 \%$ to $61.6 \%$.

Insert figure 1 about here

Sensitivity and specificity. In order to determine if the ICS score can be used to distinguish children whose parents were concerned about speech sound production from those whose parents were not concerned sensitivity and specificity were analyzed. ICS mean scores were significantly lower for children who were identified by caregivers as having difficulties in speech production $(M=3.91)$ in comparison with children who were not identified as having these difficulties $(M=4.78), p<0.001$. Sensitivity and specificity were evaluated using a Receiver Operative Characteristic (ROC) based on ICS, as presented in figure 2. Good levels of sensitivity (.80) and specificity (.84) were obtained and AUC was high (0.978). The corresponding optimal cut-point score for the sensitivity and specificity levels was 4.36 . This value is the best at discriminating between children with speech sound disorders and typically-developing children compared with the results 
obtained when a detailed assessment is used. Other cut-point values were tested, but with worse results.

Insert figure 2 about here

\section{DISCUSSION}

The aim of the present study was to analyze the reliability and validity of the European Portuguese version of the ICS. The ICS was filled out by 76 parents of European Portuguese-speaking children aged between $3 ; 9$ and $6 ; 2$. In the current study the possible influence of sociodemographic variables (gender, age, and socioeconomic status) on ICS mean scores was analyzed. There were no significant differences in the ICS scores based on gender. This result supports other previous studies using ICS (Hopf \& McDonagh, 2017; Phạm et al., 2017). In contrast, McLeod et al. (2015) found differences between male and female children (ICS scores for female children were significantly higher than those for male children). In spite of the absence of a significant difference, female children who participated in our study also received higher ICS scores than their male counterparts. Our results also indicate significantly higher ICS scores as children get older. This finding is similar to results obtained by Tomić and Mildner (2014); Phạm, McLeod, and Harrison (2017); and Neumann et al. (2017), although McLeod et al. (2015) found that children aged 5;0-5;5 received lower ICS scores than younger children. This unexpected result could be due to the fact that these children had not yet attended school. Concerning socioeconomic status, our study did not show socioeconomic influences on ICS, which is consistent to the results obtained by McLeod et al. (2015) and Hopf et al. (2017). 
A mean ICS score of 4.5 (out of a maximum of 5) was obtained by all Portuguese children. This value is similar to other ICS mean scores in international studies (e.g., $M=4.4$ for Australian children; $M=4.4$ for Vietnamese children; $M=4.4$ for German children). This means that Portuguese children are, on average, "usually" to "always" intelligible for a variety of listeners. Intelligibility was higher with parents, followed by teachers, immediate family, friends, acquaintances, and extended family; children were least intelligible to strangers. This finding is generally consistent with other studies (McLeod et al., 2012c, 2015; Neumann et al., 2017; Phạm et al., 2017) indicating the influence of environmental context on intelligibility.

The Portuguese version of the ICS presents a high internal consistency of the seven items $(\alpha=0.96)$, and moderate to high correlations between items. These results are very similar to the previous findings obtained using the original ICS (McLeod et al., 2012c, 2015).

Criterion validity was analyzed by correlating total average ICS scores for the whole sample with PPC, PCC, and PVC. The significant moderate correlation values obtained suggest that speech severity measures are correlated with parents' responses on the ICS, meaning that parents can generally characterize their children's speech skills accurately. The correlation value between PCC and ICS $(r=.65)$ is higher than the one $(r=.42)$ obtained in a previous study (Phạm et al., 2017). The results of simple linear regressions showed that we can predict the results for each severity measure (dependent variables) based on the values of the independent variable (ICS score). The values obtained for sensitivity and specificity were above 0.80 , suggesting that the ICS can be used as a screening tool to identify children who may need an in-depth assessment of their speech abilities. 
This study has some limitations that should be acknowledged. The sample size is not sufficiently large and was not systematically chosen. Participants were recruited in only three (out of a maximum of 18) districts in Portugal. Consequently, the sample is not representative of the overall population. Future studies should include a larger sample with younger children, randomly chosen. Other measures (e.g., test-retest, interrater reliability of the ICS) can be obtained to determine psychometric properties.

\section{CONCLUSIONS}

The Portuguese version of the ICS indicates strong internal consistency, criterion validity, sensitivity and specificity, meaning that the ICS is a valid and reliable measure of intelligibility for preschool-aged children. The overall good psychometric properties indicate that the Portuguese version of the ICS has clinical utility for speech-language pathologists.

\section{ACKNOWLEDGMENTS}

This work was supported by the ERDF (European Regional Development Fund) under grant POCI-01-0145-FEDER-007746 funded by the Programa Operacional Competitividade e Internacionalização - COMPETE2020 and by the National Funds through FCT - Fundação para a Ciência e a Tecnologia within CINTESIS, R\&D Unit (reference UID/IC/4255/2013) and CIDMA - Center for Research and Development in Mathematics and Applications, (reference UID/MAT/04106/2013). 


\section{REFERENCES}

Ertmer, D. J. (2010). Relationships between speech intelligibility and word articulation scores in children with hearing loss. Journal of Speech Language and Hearing Research, 53(5), 1075-1086.

Flipsen, P. (1995). Measuring the intelligibility of conversational speech in children. Clinical Linguistics and Phonetics, 20(4), 303-312.

Gay, L. R. (1985). Educational evaluation and measurement: Competencies for analysis and application (2nd ed.). Cleveland, OH: Charles E. Merrill.

Gordon-Brannan, M., \& Hodson, B. W. (2000). Intellgibility/severity measurements of prekindergarten children's speech. American Journal of Speech Language Pathology, 9, 141-150.

Hopf, S. C., \& Mcdonagh, S. H. (2017). Validation of the Intellegibility in Context Scale for school students in Fiji. Clinical Linguistics and Phonetics, 00(00), 1-16. http://doi.org/10.1080/02699206.2016.1268208

Hustad, K. C., Schueler, B., Schultz, L., \& DuHadway, C. (2012). Intelligibility of 4 year old children with and without cerebral palsy. Journal of Speech Language and Hearing Research, 55(4), 1177-1189.

Kogovšek, D., \& Ozbič, M. (2013). Lestvica razumljivosti govora v vsakdanjem življenju: slovenščina [Intelligibility in Context Scale: Slovenian]. Komunikacija, $2(3), 28-34$.

Lousada, M., Jesus, L. M., Hall, A., \& Joffe, V. (2014). Intelligibility as a clinical outcome measure following intervention with children with phonologically based speech-sound disorders. International Journal of Language and Communication Disorders, 49(5), 584-601.

Lousada, M., Mendes, A. P., Valente, A. R. S., \& Hall, A. (2012). Standardization of a 
Phonetic-Phonological Test for European Portuguese Children. Folia Phoniatrica et Logopaedica, 64, 151-156.

McLeod, S., Crowe, K., \& Shahaeian, A. (2015). Intelligibility in Context Scale:

Normative and Validation Data for English-Speaking Preschoolers. Language, Speech, and Hearing Services in Schools, 46(3), 266-276.

McLeod, S., Harrison, L. J., \& McCormack, J. (2012a). Escala de Inteligibilidad en Contexto [Intelligibility in Context Scale: Spanish] (R. Prezas, R. Rojas, \& B. A. Goldstein, Trans.).

McLeod, S., Harrison, L. J., \& McCormack, J. (2012b). Escala de Inteligibilidade em Contexto: Português Europeu [Intelligibility in Context Scale: European Portuguese]. (M. Lousada, M. Ramalho, \& J. Nascimento, Trans.). Bathurst, NSW, Australia: Charles Sturt University. Retrieved from http://www.csu.edu.au/research/multilingualspeech/ics

McLeod, S., Harrison, L. J., \& McCormack, J. (2012c). Intelligibility in Context Scale. Retrieved from http://www.csu.edu.au/research/multilingual-speech/ics McLeod, S., Harrison, L. J., \& McCormack, J. (2012d). The Intelligibility in Context Scale: Validity and Reliability of a Subjective Rating Measure. Journal of Speech, Language, and Hearing Research, 55, 648-656.

Mendes, A. P., Afonso, E., Lousada, M., \& Andrade, F. (2013). Teste FonéticoFonológico ALPE. Aveiro: Edubox.

Miller, N. (2013). Measuring up to speech intelligibility. International Journal of Language and Communication Disorders, 48(6), 601-612.

Neumann, S., Rietz, C., \& Stenneken, P. (2017). The German Intelligibility in Context Scale (ICS-G): reliability and validity evidence. International Journal of Language and Communication Disorders, 52(5), 585-594. http://doi.org/10.1111/1460- 
6984.12303

Ng, K. Y. M., To, C. K. S., \& McLeod, S. (2014). Validation of the intelligibility in context scale as a screening tool for preschoolers in Hong Kong. Clinical Linguistics \& Phonetics, 28(5), 316-328.

Pascoe, M., Stackhouse, J., \& Wells, B. (2006). Persisting Speech Difficulties in Children. In Children's Speech and Literacy Difficulties: Book 3. Chichester: Wiley.

Phạm, B., McLeod, S., \& Harrison, L. J. (2017). Validation and norming of the Intelligibility in Context Scale in Northern Viet Nam. Clinical Linguistics and Phonetics, 31(7-9), 665-681. http://doi.org/10.1080/02699206.2017.1306110

Raven, J., Raven, J. C., \& Court, J. H. (2009). Manual CPM-P: matrizes progressivas coloridas: forma paralela. Adapt. Carla Ferreira (1st ed.). Lisboa: CEGOC-TEA.

Reif, K., Marbeau, Y., Quatresooz, J., \& Vancraeynest, D. (1991). Progress report of the ESOMAR working party on harmonization of demographics. Luxembourg: ESOMAR Congress.

Saraiva, D., Lousada, M., Hall, A., \& Jesus, L. M. T. (2017). Paediatric Automatic Phonological Analysis Tools (APAT). Logopedics Phoniatrics Vocology, 42(4), $153-159$.

Shriberg, L. D., Tomblin, B., \& Mcsweeny, J. (1999). Prevalence of speech delay in 6year-old children and comorbidity with language impairment. Journal of Speech, Language and Hearing Research, 42, 1461-1481.

Tomić, D., \& Mildner, V. (2014). Validation of Croatian Intelligibility in Context Scale. Stockholm, Sweden: Poster presented at the International Clinical Phonetics and Linguistics Association Symposium.

Weismer, G. (2009). Speech intelligibility. In The handbook of Clinical Linguistic. 
Blackwell Publishing Ltd.

Williams, A. L., McLeod, S., \& McCauley, R. J. (2010). Interventions for Speech Sound Disorders in Children. Baltimore, M D: Brookes.

World Health Organization. (2007). International classification of functioning, disability and health : children \& youth version: ICF-CY. Switzerland: World Health Organization. 

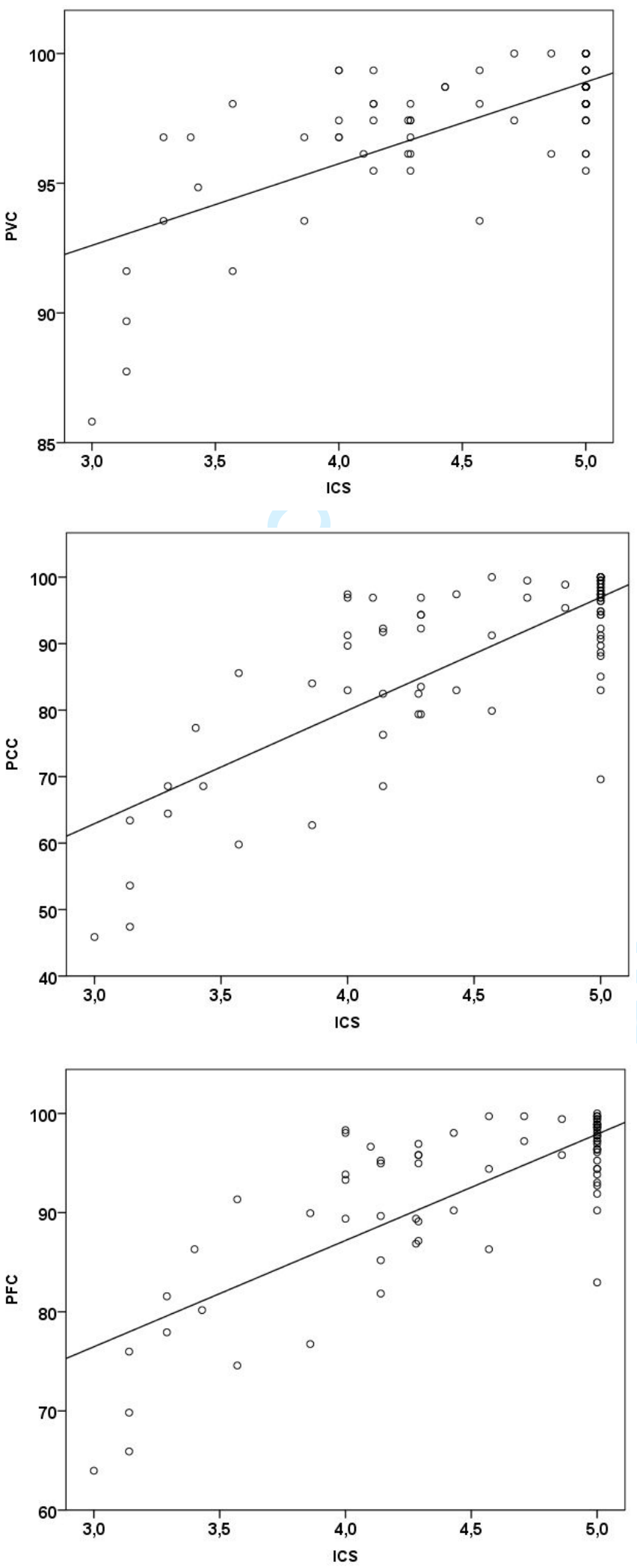

Figure 1: Simple linear regressions. Model 1(top): $\mathrm{PVC}=83.2+3.15 * \mathrm{ICS}$ (Adjusted $\mathrm{R}^{2}=0.498$ ); Model 2(middle): $\quad \mathrm{PCC}=11.9+17.02 * \mathrm{ICS} \quad$ (Adjusted $\mathrm{R}^{2}=0.602$ ); $\quad$ Model 3(bottom): $\mathrm{PPC}=44.2+10.72 * \mathrm{ICS}$ (Adjusted $\mathrm{R}^{2}=0.616$ ) 


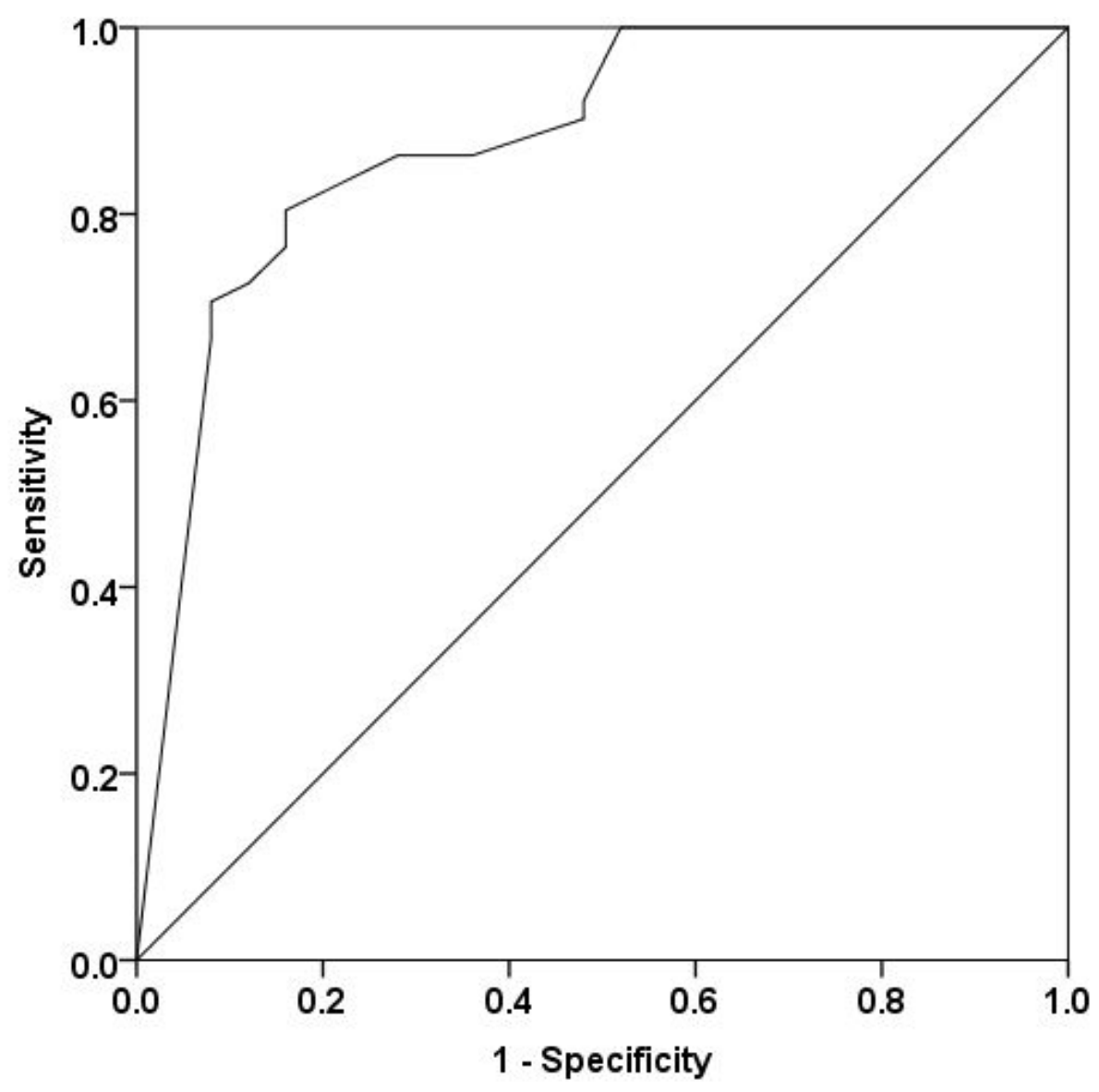

Figure 2- The Receiver Operative Characteristic (ROC). The adjusted cutoff was 4.36 that correspondent to a sensitivity level of .804 and a specificity level to .0 .840 . The AUC was 0.978 and the correspondent $95 \% \mathrm{CI}$ was $[0.792 ; 0.965]$. 
Table 1- Sociodemographic and sample characterization

\begin{tabular}{llll}
\hline Variables & $\mathrm{N}(\%)$ & & $\mathrm{N}(\%)$ \\
\hline Gender & & Socio-economic status & \\
\hline Male & $44(57.9)$ & High & $35(46.1)$ \\
\hline Female & $32(42.1)$ & Medium-High & $11(14.5)$ \\
\hline Age (months) & & Medium & $10(13.1)$ \\
\hline$\leq 53$ & $22(28.9)$ & Low & \\
\hline $54-59$ & $9(11.8)$ & & $25(32.9)$ \\
\hline $60-64$ & $19(25.0)$ & Parents evaluation & \\
\hline$\geq 65$ & $26(34.2)$ & Children with identified concern & $51(67.1)$ \\
\hline Ear infection history & & Children with no identified concern & \\
\hline Yes & $11(14.5)$ & & \\
\hline No & $65(85.5)$ & & \\
\hline Age $(M \pm S D$, months $)$ & & &
\end{tabular}


Table 2- ICS and severity scales. Values are in $\mathrm{M} \pm \mathrm{SD}$

\begin{tabular}{|c|c|c|c|c|}
\hline & ICS & PVC & PCC & $\mathrm{PFC}$ \\
\hline \multicolumn{5}{|l|}{ Gender } \\
\hline Male $(\mathrm{N}=44)$ & $4.41 \pm 0.71$ & $96.9 \pm 3.3$ & $84.7 \pm 15.5^{*}$ & $90.3 \pm 9.8$ \\
\hline Female $(\mathrm{N}=32)$ & $4.61 \pm 0.40$ & $97.9 \pm 1.5$ & $93.4 \pm 7.0^{*}$ & $95.5 \pm 4.1$ \\
\hline \multicolumn{5}{|l|}{ Age (months) } \\
\hline$\leq 53(\mathrm{~N}=22)$ & $4.11 \pm 0.70 * *$ & $95.8 \pm 3.9$ & $80.2 \pm 17.2 * *$ & $87.3 \pm 11.1^{*}$ \\
\hline $54-64(\mathrm{~N}=28)$ & $4.69 \pm 0.51 * *$ & $98.0 \pm 1.6$ & $91.7 \pm 9.2 * *$ & $94.7 \pm 5.2 *$ \\
\hline$\geq 65(\mathrm{~N}=26)$ & $4.60 \pm 0.47 * *$ & $97.8 \pm 1.7$ & $91.6 \pm 10.4^{* *}$ & $94.5 \pm 6.2^{*}$ \\
\hline \multicolumn{5}{|l|}{ Socioeconomic status } \\
\hline High $(\mathrm{N}=20)$ & $4.57 \pm 0.58$ & $97.6 \pm 1.7$ & $89.9 \pm 10.3$ & $93.5 \pm 6.2$ \\
\hline Medium-High (N=35) & $4.61 \pm 0.56$ & $97.2 \pm 2.5$ & $89.3 \pm 13.0$ & $92.9 \pm 8.1$ \\
\hline Medium $(\mathrm{N}=11)$ & $4.17 \pm 0.70$ & $96.8 \pm 3.2$ & $80.2 \pm 14.7$ & $87.8 \pm 9.1$ \\
\hline Low $(\mathrm{N}=10)$ & $4.30 \pm 0.60$ & $97.5 \pm 4.2$ & $90.9 \pm 16.2$ & $93.9 \pm 10.8$ \\
\hline \multicolumn{5}{|l|}{ Parents evaluation } \\
\hline $\begin{array}{l}\text { Children with identified concern } \\
(\mathrm{N}=25)\end{array}$ & $3.91 \pm 0.59 * * *$ & $95.1 \pm 3.5 * * *$ & $73.9 \pm 13.7 * * *$ & $83.6 \pm 8.9 * * *$ \\
\hline $\begin{array}{l}\text { Children with no identified } \\
\text { concern }(\mathrm{N}=51)\end{array}$ & $4.78 \pm 0.36^{* * *}$ & $98.4 \pm 1.2 * * *$ & $95.4 \pm 4.4 * * *$ & $96.8 \pm 2.4 * * *$ \\
\hline
\end{tabular}


Table 3-Parent ratings for the 7-item in ICS $(\mathrm{N}=76)$

\begin{tabular}{llccccc}
\hline & & $\begin{array}{c}\text { Always } \\
(5)\end{array}$ & $\begin{array}{c}\text { Usually } \\
(4)\end{array}$ & $\begin{array}{c}\text { Sometimes } \\
(3)\end{array}$ & $\begin{array}{c}\text { Rarely } \\
(2)\end{array}$ & $\begin{array}{c}\text { Never } \\
(1)\end{array}$ \\
\hline Item & $\mathrm{M} \pm \mathrm{SD}$ & $\mathrm{N}(\%)$ & $\mathrm{N}(\%)$ & $\mathrm{N}(\%)$ & $\mathrm{N}(\%)$ & $\mathrm{N}(\%)$ \\
\hline $\begin{array}{l}\text { Do you understand your child? } \\
\text { Do immediate members of } \\
\text { your family understand your } \\
\text { child? }\end{array}$ & $4.75 \pm 0.49$ & $59(77.6)$ & $15(19.7)$ & $2(2.6)$ & $0(0)$ & $0(0)$ \\
$\begin{array}{l}\text { Do extended members of your } \\
\text { family understand your child? }\end{array}$ & $4.55 \pm 0.60$ & $46(60.5)$ & $26(34.2)$ & $4(5.3)$ & $0(0)$ & $0(0)$ \\
$\begin{array}{l}\text { Do your child's friends } \\
\text { understand your child? }\end{array}$ & $4.49 \pm 0.74$ & $47(61.8)$ & $20(26.3)$ & $8(10.5)$ & $1(1.3)$ & $0(0)$ \\
$\begin{array}{l}\text { Do other acquaintances } \\
\text { understand your child? }\end{array}$ & $4.41 \pm 0.72$ & $41(53.9)$ & $25(32.9)$ & $10(13.2)$ & $0(0)$ & $0(0)$ \\
$\begin{array}{l}\text { Do your child's teachers } \\
\text { understand your child? }\end{array}$ & $4.61 \pm 0.57$ & $49(54.5)$ & $24(31.6)$ & $3(3.9)$ & $0(0)$ & $0(0)$ \\
$\begin{array}{l}\text { Do strangers understand your } \\
\text { child? }\end{array}$ & $4.33 \pm 0.81$ & $39(51.3)$ & $25(32.9)$ & $10(13.2)$ & $2(2.6)$ & $0(0)$ \\
\hline
\end{tabular}


Table 4-Inter-item correlations for the ICS $(\mathrm{N}=76)$.

\begin{tabular}{|c|c|c|c|c|c|c|c|}
\hline & $\begin{array}{l}1 . \\
\text { Parent }\end{array}$ & $\begin{array}{l}2 . \\
\text { Immediate } \\
\text { family }\end{array}$ & $\begin{array}{l}3 . \\
\text { Extended } \\
\text { family }\end{array}$ & $\begin{array}{l}4 . \\
\text { Child's } \\
\text { friends }\end{array}$ & $\begin{array}{l}5 . \\
\text { Acquaintances }\end{array}$ & $\begin{array}{l}6 . \\
\text { Teachers }\end{array}$ & $\begin{array}{l}7 . \\
\text { Strangers }\end{array}$ \\
\hline 1. Parent & 1 & 0.70 & 0.62 & 0.70 & 0.71 & 0.74 & 0.68 \\
\hline $\begin{array}{l}\text { 2. Immediate } \\
\text { family }\end{array}$ & & 1 & 0.79 & 0.79 & 0.87 & 0.77 & 0.81 \\
\hline $\begin{array}{l}\text { 3. extended } \\
\text { family }\end{array}$ & & & 1 & 0.83 & 0.89 & 0.69 & 0.84 \\
\hline $\begin{array}{l}\text { 4. Child's } \\
\text { friends }\end{array}$ & & & & 1 & 0.90 & 0.74 & 0.86 \\
\hline $\begin{array}{l}5 . \\
\text { Acquaintances }\end{array}$ & & & & & 1 & 0.80 & 0.94 \\
\hline 6. Teachers & & & & & & 1 & 0.78 \\
\hline
\end{tabular}

